\title{
THE PERFORMANCE AND ASSET ALLOCATION OF GERMAN ROBO-ADVISORS ${ }^{1}$
}

\author{
MICHAEL PUHLE \\ Department of Finance, Corvinus University Budapest, Hungary \\ Email: michael.puhle@uni-corvinus.hu
}

\begin{abstract}
After a short historical perspective on the emergence of robo-advisors and an overview of how they manage other people's money, we evaluate the performance of five German robo-advisors in the period between May 2015 and December 2018. Performance tests are conducted using Sharpe's (1966) and Jensen's (1968) performance methodologies. We also employ the returns-based style analysis of Sharpe (1992) to determine the exposure of robo-advisors to different non-overlapping asset classes. We report the following findings: First, no robo-advisor was able to beat the benchmark before or after considering fees. Second, robo-advisor performance varies greatly in the sample period even for portfolios that should appeal to clients with similar risk preferences. Third, these performance differences remain unexplained after accounting for the different asset allocations.
\end{abstract}

Keywords: robo-advisor, robo-advise, FinTech, style analysis

JEL-codes: G11, G21, G23

1 This work was supported by the Hungarian National Research, Development and Innovation Office under project 2018-1.3.1-VKE. 


\section{INTRODUCTION}

This article compares actual performances of five German robo-advisors over the May 2015 - December 2018 period, and explains performance differences between them using returns-based style analysis (Sharpe 1992). Returns-based style analysis tries to "reverse-engineer" the actual asset allocation of a portfolio using statistical methods. It must be contrasted with holdings-based style analysis, which tries to determine the investment style by looking at the individual portfolio holdings.

Robo-advisors can be defined as "automated online services that use computer algorithms to provide financial advice and manage customers' investment portfolios" (Fisch et. al. 2018). The first robo-advisors have been founded in the United States in 2010. Since robo-advisors are a relatively recent phenomenon, the academic literature covering the topic is still very scarce. Lam (2016) and Puhle (2016) describe the evolution, regulation and inner workings of robo-advisors. A more recent source, Fisch et al. (2018), focuses on the historical development and future challenges of robo-advisors and analyzes their impact on retirement planning. We are not aware of any article that analyses the performance and asset allocation of robo-advisors in detail. Backend Benchmarking publishes a quarterly report covering US robo-advisors' performance (The Robo Report) but this analyzes the performances not in the same detail as we do.

The performance of mutual funds has been analyzed extensively though, starting with the seminal work of Jensen (1968). A more recent analysis focusing on equity managers is Bhargava et al. (2001).

This paper contributes to the literature in two ways. First, we analyze the actual performances of German robo-advisors using descriptive statistics and returnsbased style analysis. Second, we document significant performance differences between robo-advisors. The portfolios that we analyze have a similar asset allocation and should hence appeal to people with a similar risk preference. This finding suggests that robo-advisors manage portfolios in different ways and choosing the wrong robo-advisor has a significant negative impact on terminal wealth.

The paper is organized as follows. We introduce robo-advisors in Section 2. Section 3 explains how robo-advisors typically manage clients' money. In Secion 4, we analyze the historical performance of five German robo-advisors in detail. Section 5 concludes the article. 


\section{WHAT ARE ROBO-ADVISORS?}

Richard J. Koreto coined the term "robo-advisor" in an article he wrote for the magazine Financial Planning, but his robo bears no resemblance to today's roboadvisors (Koreto 2002) What do we mean nowadays, when we refer to roboadvisors? Investopedia defines robo-advisors as "an online wealth management service that provides automated, algorithm-based portfolio management advice without the use of human financial planners". According to Wikipedia, robo-advisors are "a class of financial adviser that provides financial advice or portfolio management online with minimal human intervention." Both definitions point to three important characteristics of robo-advisors: they provide (i) an automated investment solution, (ii) that is digitally delivered and (iii) uses algorithms to recommend asset allocations to customers.

Robo-advisors are a global phenomenon. The first robo-advisor, Betterment, started in the United States in 2010 and is currently the largest independent roboadvisor with around $\$ 9$ billion assets under management (AuM), followed by Wealthfront with $\$ 7$ billion AuM. The largest robo-advisors in the United States are those owned by fund managers, brokers or banks though: Vanguard Personal Advisor Services, which was founded in 2015 manages already $\$ 83$ billion and Schwab Intelligent Portfolios is the number two robo-advisor with $\$ 19$ billion AuM. Figure 1 shows that robo-advisors - seven years after they first appeared - are still being launched, but nowadays mainly by fund managers, brokers or banks. In late 2017 or early 2018, we expected to see launches from Morgan Stanley, Wells Fargo, and Goldman Sachs. A.T. Kearney estimates the U.S. roboadvisor market to be around to $\$ 2.2$ trillion in 2012 (A. T. Kearney 2015).

Europe is the second largest robo-advisor market after North America. The first robo-advisor that was launched in Europe is nutmeg (United Kingdom, 2011). The first German robo-advisor, Quirion, appeared in 2013. Quirion is a subsidiary of the Berlin-based Quirin Bank, a private bank focusing on wealth management. The first independent robo-advisors, Ginmon and Vaamo, appeared

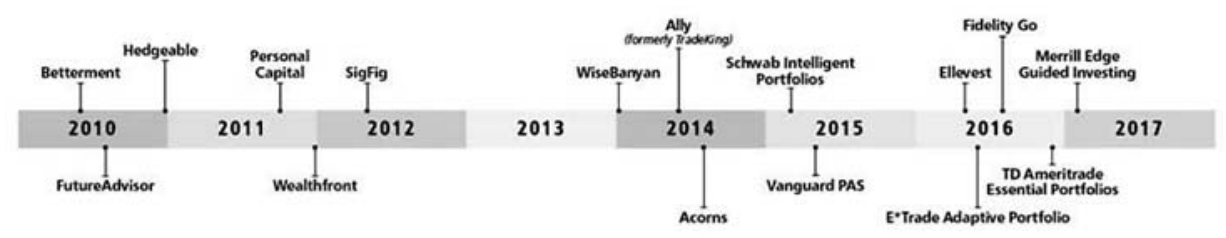

Figure 1. US robo-advisor launch timeline.

Source: Barron's (2017) 


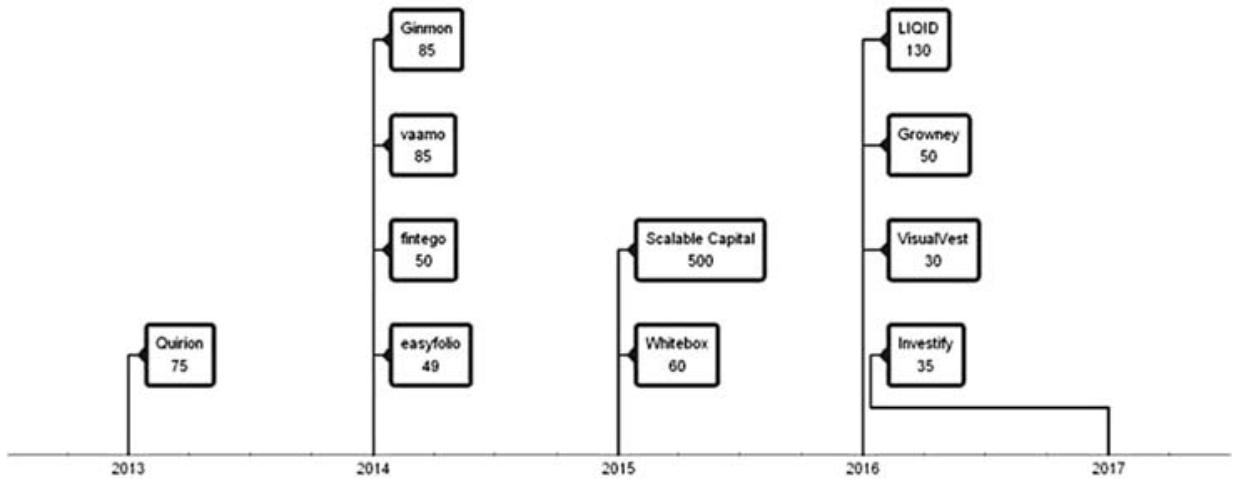

Figure 2. German robo-advisor launch timeline with estimated AuM in $€$ million Source: author's estimates based on Extra-Magazin (2017), TechFluence (2017) and company press releases.

in 2014. Germany, the focus of this article, is an important market for robo advice not only in Europe but worldwide. According to some sources, in November 2017 there were 31 robo-advisors operating in Germany (TechFluence 2017) with an estimated $€ 1.5$ billion AuM. ${ }^{2}$

Scalable Capital leads the market in Germany with $€ 500$ million AuM and 15,000 clients followed by Liqid with €130 million AuM and 400 clients. Because of a minimum investment of $€ 100,000$, Liqid focuses on more wealthy individuals and hence has a smaller number of clients. Scalable Capital is also number two in Europe - after UK-based nutmeg (AuM €700 million). Exact AuM numbers are generally hard to come by since there is no mandatory reporting as there is, for example, in the United States (reported in Form ADV documents). Therefore, we need to rely on self-reporting by companies. With more than 30 robo-advisors fighting for clients, only well-established companies are open to AuM- and client number reporting. ${ }^{3}$ Figure 2 shows the launch timeline and a current estimate of German robo-advisor AuM in $€$ million.

In the Asia/Pacific region, robo-advisors appeared relatively late. We have seen launches only in the last couple of years. Bambu, a leading B2B robo-advisor in Singapore was launched in February 2016 for example. The Asia/Pacific region is a little late because of the relative scarcity of available exchange traded funds (ETF), which are normally used by robo-advisors to implement the portfolios

2 Author's estimate based on data from TechFluence (2017), Extra-Magazin (2017) and company reports.

3 Only Scalable Capital and Liqid have released press releases with detailed information on AuM, client numbers and client characteristics. 
they recommend. Besides established banks, there are also a couple of independent robo-advisors that have been launched or are in the process of launching across Asia and the Pacific: Ignition Wealth (Australia), Lingji (China), Chloe (Hong Kong), Theo (Japan), and Smartly and Bambu (Singapore). IDC (2017) estimated in a November 2017 report that AuM in Asia/Pacific will grow to \$500 billion by 2021.

\section{HOW DO ROBO-ADVISORS MANAGE CLIENTS' MONEY?}

In Germany, there exist currently around 30 robo-advisors (Micobo 2018) and all of them seem to tout their superior investment model. A closer look reveals though that nearly all investment models are firmly rooted in modern portfolio theory (MPT). Hence, one would not expect much performance differences between recommended portfolios for people with similar risk preferences.

Most robo-advisors use portfolio models in the tradition of modern portfolio theory (see e.g. Markowitz 1952 and Sharpe 1964) to manage money for clients. In order to recommend specific portfolios to investors, robo-advisors first need to establish a set of suitable (or in some cases even efficient) portfolios. The roboadvisor then selects one portfolio from this set that is most suitable for the client, e.g. corresponds to their risk preference.

The first step in this procedure is to establish the investment universe, i.e. the set of asset classes in which to invest in. Research shows that asset allocation is one of the most important drivers of portfolio returns (and not e.g. individual security selection), so robo-advisors focus on asset classes and not individual securities. The investment universe of typical robo-advisors consists of domestic and international stocks (both developed and emerging markets), government and corporate bonds (both potentially from developed and emerging markets). Some robo-advisors include more exotic asset classes like treasury inflation-protected securities (TIPS), real estate, commodities or precious metals. The main goal is to have portfolio with exposures to many diverse risk factors. However, one also has to be aware of the implementation problem. The asset classes should be easily investable for example via an ETF. Some asset classes that would offer diversification potential are unfortunately out-of-reach for the typical retail investor, e.g. private equity investments and hedge funds. They have high minimum investment requirements and are hence usually not included in the investment universe. However, there are exceptions. Liqid, the number two robo-advisor in Germany, with a focus on wealthy individuals offers indirect investment in private equity funds. The number and the composition of the investment universe differs from robo-advisor to robo-advisor, but usually between 5 and 15 
asset classes are included: Scalable Capital includes 6 major asset classes and Wealthfront includes 11. Each asset class is then mapped to one or more concrete investment assets, e.g. the asset class US Large Cap Equity could be mapped to an iShares S\&P 500 ETF.

In the second step, parameters of the multi-variate asset class return distribution are estimated. In a mean-variance framework, one has to estimate means and variances of asset class returns and the correlations between the different asset classes. This input is then fed into an optimizer, which outputs the portfolio with the maximum expected return for a given level of risk. Unfortunately, the optimizer is very sensitive to changes in inputs (especially the means) and the resulting asset class weights are often non-sensible (Michaud 1989) A couple of methods have been proposed to deal with this problem, mainly constrained optimization and the Black/Litterman approach (Black - Litterman 1992). Wealthfront includes minimum and maximum weights for each asset class in the optimization procedure and uses the Black/Litterman model to estimate sensible asset class expected returns, which it updates with internal views regarding the performance of the asset classes.

Not all robo-advisors use the mean-variance framework for the optimization problem selection: Scalable Capital for example uses a mean-Value-at-Risk (VaR) framework. Other robo-advisors are not even employing a formal optimization method but instead construct portfolios using approaches that are more heuristic.

The last step consists of recommending one specific portfolio from the efficient set to a client. To accomplish this, robo-advisors ask clients to fill out risk profile questionnaires and estimates the client's risk preference from the given answers. Once the risk preference has been established, the corresponding portfolio is recommended. In the early days, the set of portfolios was small: Vaamo used 3 portfolios differing only in their weights to the target asset classes and Ginmon used 11 portfolios. Scalable Capital constructs 23 different portfolios ranging from a $2 \% \mathrm{VaR}$ (1 year, 99\%) to $25 \% \mathrm{VaR}$.

After establishing the initial portfolio, robo-advisors monitor the portfolio and apply changes to it, when market conditions or the risk preferences of the client change. Even if model inputs do not change, simply by being invested in the markets, the actual asset class weights diverge from the proposed weights over time. These weights are brought back to their recommended levels in a process that is called rebalancing. Rebalancing can be done at specific points in time (e.g. yearly) or done on an event-based basis (e.g. when the divergence between actual and recommended weights is large).

For a more detailed discussion of the mechanics of robo-advisor investing, see Lam (2016), Puhle (2016) or Fisch et al. (2018). 


\section{HOW ARE ROBO-ADVISORS PERFORMING?}

Robo-advisors differ in their investment methodology, described above and tout their uniqueness. In the end, what matters is portfolio performance. Of course, to evaluate robo-advisor offerings one has to take into account several characteristics, e.g. investment methodology, ease-of-use, fees - but surely also performance.

Unfortunately, in the past it was hard or impossible to get reliable portfolio performance figures from robo-advisors. Recently reports have been published containing performance figures from portfolios funded with real money. In Germany, the internet portal BrokerVergleich publishes monthly performance data for 16 robo-advisor portfolios (BrokerVergleich 2018). In the United States, Backend Benchmarking publishes quarterly robo-advisor performance figures (Backend Benchmarking 2019)

We analyze whether robo-advisors can deliver a performance similar to a benchmark performance. Furthermore, we look at differences between individual robo-advisor returns and try to explain them.

\subsection{Data}

Our data consists of monthly performance figures reported by the German internet portal BrokerVergleich.de (BrokerVergleich 2019). BrokerVergleich.de currently tracks the performance of investment accounts at 16 German robo-advisors, all of which it has funded with real money. Of the 16 accounts, five have been opened in May 2015, three have been added in May 2016, three in May 2017 and a further five in May 2018.

In our current study, we focus on the five portfolios that cover the longest interval, from May 2015 to December 2018. To make the performance figures comparable even for the nonprofessional, BrokerVergleich.de opened accounts for an individual with a moderate risk preference, resulting in each case in a portfolio of roughly $50 \%$ equities and $50 \%$ fixed income. The equity part of the portfolios is usually internationally invested in developed and emerging market stocks, but the fixed income part mainly in European government and corporate bonds. Table 1 contains information on the tracked robo-advisor portfolios. 
Table 1. Coverage data for robo advisors

\begin{tabular}{lcc}
\hline & Initialization of coverage & Number of observations \\
\hline Easyfolio & $2015-05$ & 44 \\
\hline Fintego & $2015-05$ & 44 \\
\hline Quirion & $2015-05$ & 44 \\
\hline SutorBank & $2015-05$ & 44 \\
\hline Vaamo & $2015-05$ & 44 \\
\hline GINMON & $2016-05$ & 32 \\
\hline Scalable Capital & $2016-05$ & 32 \\
\hline Whitebox & $2016-05$ & 32 \\
\hline Growney & $2017-05$ & 20 \\
\hline Investify & $2017-05$ & 20 \\
\hline VisualVest & $2017-05$ & 20 \\
\hline Cominvest & $2018-05$ & 8 \\
\hline Prospery & $2018-05$ & 8 \\
\hline ROBIN & $2018-05$ & 8 \\
\hline Solidvest & $2018-05$ & 8 \\
\hline WeltInvest & $2018-05$ & 8 \\
\hline
\end{tabular}

Source: author's calculations based on data from BrokerVergleich.

\subsection{Empirical Results}

\subsubsection{Distribution of monthly returns}

First, we analyze the reported monthly returns and estimate parameters of the sample return distributions. We report the results in Table 2.

There exists considerable variation between the return distributions of the robo-advisor portfolios. The monthly sample mean varies between $-0.055 \%$ and $0.064 \%$ and the sample standard deviation between $1.827 \%$ and $2.102 \%$. All portfolios exhibit negative skewness and excess kurtosis. The monthly minimum and maximum returns in the sample vary between $-5.3 \%$ and $-4.2 \%$ and $4.3 \%$ and $5.1 \%$ respectively.

We also constructed benchmark returns. We construct the benchmark as an equally weighted portfolio consisting of the MSCI World Index (EUR) and the Bloomberg Barclays Global Aggregate Total Return Index (Hedged in EUR). Because the robo-advisors in our sample do not engage in active portfolio management and hence are not trying to beat the benchmark, we calculated both before-fee (gross) benchmark returns and after-fee (net) benchmark returns. We calculated net benchmark returns by subtracting typical ETF management fees 
Table 2. Descriptive statistics for robo-advisor and benchmark returns (monthly data)

\begin{tabular}{lc|c|c|c|cc}
\hline & $\begin{array}{c}\text { Arithmetic } \\
\text { Mean (\%) }\end{array}$ & $\begin{array}{c}\text { Standard } \\
\text { Deviation } \\
(\%)\end{array}$ & Skewness & $\begin{array}{c}\text { Excess } \\
\text { Kurtosis }\end{array}$ & $\begin{array}{c}\text { Min } \\
\text { (\%) }\end{array}$ & $\begin{array}{c}\text { Max } \\
\text { (\%) }\end{array}$ \\
\hline \multicolumn{7}{c}{ Robo-advisor } \\
\hline Easyfolio & -0.055 & 1.827 & -0.363 & 1.175 & -5.000 & 4.900 \\
\hline Fintego & -0.002 & 1.840 & -0.472 & 0.766 & -4.400 & 4.600 \\
\hline Quirion & 0.041 & 1.868 & -0.407 & 0.774 & -4.200 & 4.900 \\
\hline SutorBank & -0.043 & 2.102 & -0.410 & 0.661 & -5.300 & 5.100 \\
\hline Vaamo & 0.064 & 1.834 & -0.250 & 0.175 & -4.600 & 4.300 \\
\hline \multicolumn{7}{c}{ Benchmark } \\
\hline Before fees & 0.174 & 1.707 & -0.346 & 0.856 & -4.112 & 4.669 \\
\hline After fees & 0.063 & 1.707 & -0.346 & 0.856 & -4.224 & 4.557 \\
\hline
\end{tabular}

Note: Benchmark data is from Bloomberg.

Source: author.

and typical robo-advisor fees from the gross benchmark returns. ${ }^{4}$ In our opinion, after-fee benchmark returns are more appropriate for contrasting with robo-advisor returns.

Only Vaamo has a mean return that is higher than the after-fee benchmark return. No robo-advisor achieved an average monthly return that is higher than the gross benchmark mean return. Implementation costs, i.e. ETF management fees and robo-advisor fees reduce portfolio performance considerably.

The monthly returns of the five robo-advisors are highly correlated as the covariance/correlation matrix in Table 3 shows. This is not surprising since the tracked portfolios have a similar asset allocation (on average $50 \%$ equity and $50 \%$ fixed income). The minimum correlation coefficient is $85.9 \%$ (between Fintego and Vaamo) and the highest correlation coefficient exists between Quirion and SutorBank (94.8\%).

Table 3. Covariance/correlation matrix of robo-advisor portfolios

\begin{tabular}{lc|c|c|cc}
\hline & Easyfolio & Fintego & Quirion & SutorBank & Vaamo \\
\hline Easyfolio & 3.262 & 0.939 & 0.943 & 0.944 & 0.933 \\
\hline Fintego & 3.084 & 3.309 & 0.931 & 0.899 & 0.859 \\
\hline Quirion & 3.143 & 3.128 & 3.408 & 0.948 & 0.920 \\
\hline SutorBank & 3.542 & 3.398 & 3.635 & 4.317 & 0.930 \\
\hline Vaamo & 3.053 & 2.831 & 3.078 & 3.502 & 3.285 \\
\hline
\end{tabular}

Source: author.

$4 \quad$ We assumed a management fee of $0.38 \%$ p.a. for an ETF that tracks the MSCI World Index and a management fee of $0.3 \%$ p.a. for an ETF that tracks the Bloomberg Barclays Global Aggregate Index. Furthermore, we assume a typical robo-advisor fee of $1 \%$ p.a. 


\subsubsection{Cumulative performance}

After having analyzed the monthly returns, we turn our attention to the cumulative performance of robo-advisors from May 2015 until December 2018, which is shown in Figure 3.

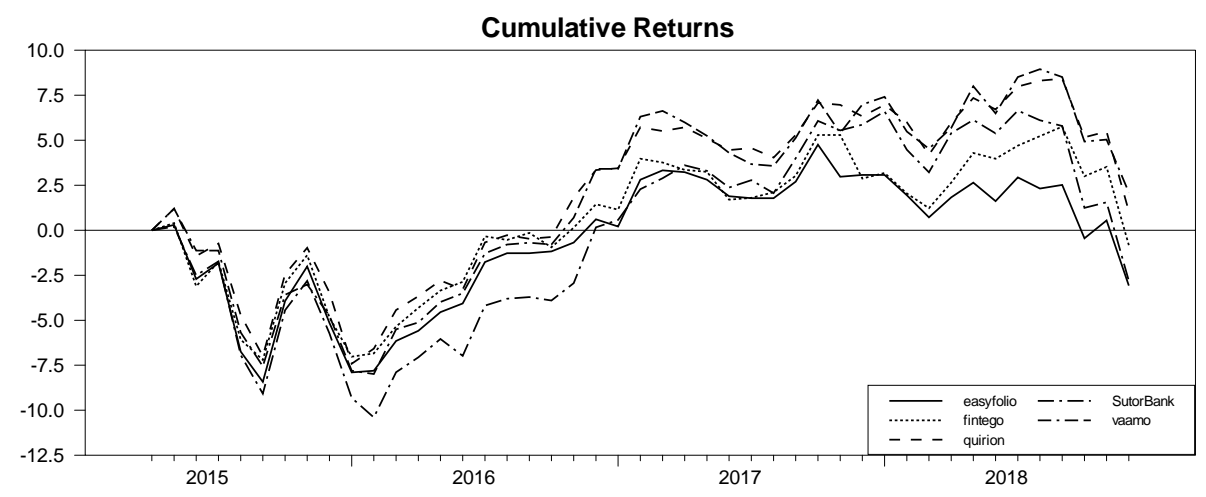

Figure 3. Cumulative performance of robo-advisors in percentage, from May 2015 to December 2018

Source: author.

Cumulative performance is similar between the robo-advisors except for SutorBank and Easyfolio. SutorBank drops much more in the beginning of 2016 but gains more on a relative basis during the period until December 2018. In risk terminology, this refers to a much higher maximum drawdown of $10.6 \%$ for SutorBank. Maximum drawdowns (MDD) for all robo-advisors are reported in Table 4.

Table 4. Maximum drawdown for robo-advisors

\begin{tabular}{lc}
\hline Robo-Advisor & MDD (\%) \\
\hline Easyfolio & 8.7 \\
\hline Fintego & 7.6 \\
\hline Quirion & 8.6 \\
\hline SutorBank & 10.6 \\
\hline Vaamo & 9.2 \\
\hline
\end{tabular}

Source: author. 
Table 5 reports the cumulative performance in each calendar year and since inception.

Table 5. Cumulative performance per calendar year

\begin{tabular}{lc|c|c|cc}
\hline & $2015 *$ & 2016 & 2017 & 2018 & \multirow{2}{*}{ Since inception } \\
\hline Easyfolio & $-5.1 \%$ & $6.1 \%$ & $2.5 \%$ & $-6.0 \%$ & $-3.1 \%$ \\
\hline Fintego & $-4.8 \%$ & $6.6 \%$ & $1.4 \%$ & $-3.6 \%$ & $-0.8 \%$ \\
\hline Quirion & $-3.5 \%$ & $7.0 \%$ & $2.9 \%$ & $-5.0 \%$ & $1.1 \%$ \\
\hline SutorBank & $-5.7 \%$ & $6.3 \%$ & $5.7 \%$ & $-8.2 \%$ & $-2.8 \%$ \\
\hline Vaamo & $-4.8 \%$ & $8.6 \%$ & $3.5 \%$ & $-4.6 \%$ & $2.1 \%$ \\
\hline \multicolumn{7}{c}{ Benchmark } \\
\hline Before fees & $-1.2 \%$ & $6.7 \%$ & $4.3 \%$ & $-2.4 \%$ & $7.3 \%$ \\
\hline After fees & $-2.1 \%$ & $5.3 \%$ & $2.9 \%$ & $-3.7 \%$ & $2.2 \%$ \\
\hline
\end{tabular}

* from 30 April

Source: author.

When we look at the returns since inception, no robo-advisor has been able to beat the benchmark on a before-fee basis and only Vaamo has achieved nearly the same performance after fees. Vaamo is the best-performing robo-advisor and Easyfolio the worst performing, with a 5.2\% performance gap between them.

When we analyze the individual years, we find that in 2016 Quirion and Vaamo have been able to beat the index even before fees. In 2015, on the other hand, all robo-advisors performed worse than the index even on an after-fee basis. This might suggest that the asset allocation of the robo-advisors does not closely follow the 50\% MSCI World and 50\% Bloomberg Barclays Global Aggregate composition, but includes other asset classes as well. In addition, different rebalancing methodologies or ETF choice might have had an influence.

We report the relative performance of the individual robo-advisors in Table 6. In our small sample, we observe that no robo-advisor was consistently better or worse than its peers. Monthly robo-advisor returns also do not display significant autocorrelations.

In the next sections, we compare the robo-advisors regarding different riskadjusted performance measures. 
Table 6. Annual robo-advisor rankings with annual performance in percent

\begin{tabular}{cc|c|cc}
\hline Rank & $2015 *$ & 2016 & 2017 & 2018 \\
\hline 1 & Quirion & Vaamo & SutorBank & Fintego \\
& $-3.5 \%$ & $8.6 \%$ & $5.7 \%$ & $-3.6 \%$ \\
\hline 2 & Vaamo & Quirion & Vaamo & Vaamo \\
& $-4.8 \%$ & $7.0 \%$ & $3.5 \%$ & $-4.6 \%$ \\
\hline 3 & Fintego & Fintego & Quirion & Quirion \\
& $-4.8 \%$ & $6.6 \%$ & $2.9 \%$ & $-5 . \%$ \\
\hline 4 & Easyfolio & SutorBank & Easyfolio & Easyfolio \\
& $-5.1 \%$ & $6.3 \%$ & $2.5 \%$ & $-6.0 \%$ \\
\hline 5 & SutorBank & Easyfolio & Fintego & SutorBank \\
& $-5.7 \%$ & $6.1 \%$ & $1.4 \%$ & $-8.2 \%$ \\
\hline
\end{tabular}

* from 30 April

Source: author.

\subsubsection{Sharpe Ratio}

The Sharpe ratio measures the excess return earned per unit of total risk. $S R_{i}$ is computed as

$$
S R_{i}=\frac{\mu_{i}-r_{f}}{\sigma_{i}},
$$

where, for robo-advisor $i, \mu_{i}$ is the sample mean monthly return, $r_{f}$ is the mean monthly 1-month EURIBOR return, and $\sigma_{i}$ is the standard deviation of the monthly return for robo-advisor $i$. We report Sharpe ratios for roboadvisors and the benchmark in Table 7.

Table 7. Sharpe-ratios for robo-advisors and benchmark.

\begin{tabular}{|c|c|}
\hline & Sharpe Ratio \\
\hline \multicolumn{2}{|c|}{ Robo-advisor } \\
\hline Easyfolio & -0.02 \\
\hline Fintego & 0.01 \\
\hline Quirion & 0.04 \\
\hline SutorBank & -0.01 \\
\hline Vaamo & 0.05 \\
\hline \multicolumn{2}{|c|}{ Benchmark } \\
\hline Before fees & 0.26 \\
\hline After fees & 0.20 \\
\hline
\end{tabular}

Source: author. 


\subsubsection{Jensen's alpha}

We also evaluate robo-advisors using the following model (Jensen 1968):

$$
r_{i t}=\alpha_{i}+\beta_{i} r_{M}+\varepsilon_{i},
$$

where $r_{i t}$ is the excess monthly robo-advisor return, $r_{M}$ is the monthly excess return of the market. We use the MSCI World Index as a proxy for the market and calculate the excess return over the $1 \mathrm{M}$ Euribor returns. The estimated $\alpha_{i}$ and $\beta_{i}$ for all robo-advisors and the benchmark are reported in Table 8 .

Table 8. Jensen's alpha and beta.

\begin{tabular}{|c|c|c|}
\hline & Beta & Jensen's alpha \\
\hline \multicolumn{3}{|c|}{ Robo-advisors } \\
\hline Easyfolio & 0.494 & -0.192 \\
\hline Fintego & 0.491 & -0.139 \\
\hline Quirion & 0.520 & -0.106 \\
\hline SutorBank & 0.567 & -0.205 \\
\hline Vaamo & 0.487 & -0.072 \\
\hline \multicolumn{3}{|c|}{ Benchmark } \\
\hline Before fees & 0.486 & 0.039 \\
\hline After fees & 0.486 & -0.072 \\
\hline
\end{tabular}

Source: author.

The estimated values for Jensen's alpha are all negative and not statistically significant even at the $10 \%$ level. Negative values for alpha indicate that the robo-advisors performed worse than their exposure to the market portfolio would warrant. In our case, this is not surprising since robo-advisors do not perform active portfolio management and robo-advisor returns are after fees. Their stated goal is not to beat the market but simply to invest the clients' money in the markets in a way that suits their risk preference.

Next, we look at the asset-allocation decision of the robo-advisors in our sample to gain some further understanding of why some robo-advisors performed better than others.

\subsubsection{Asset allocation}

To capture exposures to typical asset classes, we analyze each robo-advisor return time series using a common factor set across all portfolios. To run our analysis, we selected five typical asset classes in which robo-advisors invest: developed market bonds (government and corporate), developed market equity, emerging 
market equity, treasury inflation-protected bonds (TIPS) and commodities. We report summary statistics for these asset classes in Table 9.

Table 9. Summary statistics for monthly asset class returns, from May 2015 to December 2018

\begin{tabular}{lc|c|c|r|rr}
\hline Asset class & $\begin{array}{c}\text { Arithmetic } \\
\text { Mean (\%) }\end{array}$ & $\begin{array}{c}\text { Standard } \\
\text { Deviation } \\
(\%)\end{array}$ & Skewness & $\begin{array}{c}\text { Excess } \\
\text { Kurtosis }\end{array}$ & Min (\%) & Max (\%) \\
\hline Bonds DM & 0.043 & 0.696 & -0.063 & 0.751 & -1.832 & 1.792 \\
\hline Equity DM & 0.306 & 3.442 & -0.442 & 0.845 & -8.485 & 9.057 \\
\hline Equity EM & 0.045 & 3.849 & -0.234 & 0.319 & -10.315 & 8.258 \\
\hline TIPS & 0.017 & 1.218 & -0.337 & -0.741 & -2.378 & 2.241 \\
\hline Commodities & -0.596 & 3.479 & -0.106 & 0.629 & -9.859 & 7.981 \\
\hline
\end{tabular}

Source: author.

The covariance/correlation matrix for the asset class (factor) returns is given in Table 10.

Table 10. Covariance/correlation matrix of asset class returns

\begin{tabular}{|l|c|c|c|c|c|}
\hline & Bonds DM & Equity DM & Equity EM & TIPS & Commodities \\
\hline Bonds DM & 0.580 & -0.073 & 0.029 & 0.663 & -0.132 \\
\hline Equity DM & -0.197 & 12.632 & 0.755 & 0.207 & 0.376 \\
\hline Equity EM & 0.116 & 13.912 & 26.901 & 0.273 & 0.448 \\
\hline TIPS & 0.738 & 1.074 & 2.071 & 2.140 & 0.072 \\
\hline Commodities & -0.403 & 5.344 & 9.298 & 0.420 & 15.979 \\
\hline
\end{tabular}

Source: author.

The asset classes are quite uncorrelated to each other. The highest correlation (75.5\%) is observed between developed market equity and emerging market equity, the lowest correlation (-13.2\%) exists between developed market bonds and commodities.

Figure 4 reports the cumulative performance of the individual asset classes over the sample period.

Emerging markets equity and commodities were the big losers until Q1 2016. Afterwards, emerging markets equity rebounded. Commodities markets were the worst performer with a return of approximately $-20 \%$. Over our period, a portfolio fully invested in developed markets equity would have outperformed all peers, whereas even a small exposure to commodities would have been a serious drag on performance. 


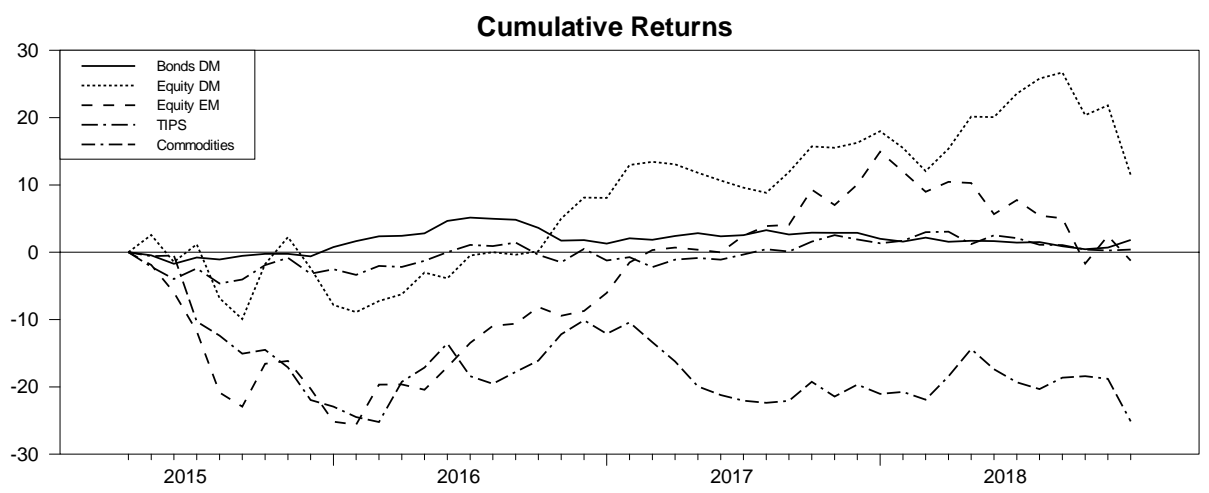

Figure 4. Cumulative performance of different asset classes in percentages, from May 2015 to December 2018

Source: author.

We employ style analysis developed by Sharpe (1992) to infer the effective exposures of each robo-advisor to mutually exclusive asset classes. The effective mix method contrasts with one that measures the asset class exposure based on the reported holdings - return-based versus holdings-based style analysis. The results provide a guide for assessing the source of robo-advisor returns.

In order to estimate the exposure, we run a constrained regression. We regress monthly robo-advisor returns on the above-mentioned returns of the five asset classes. We also require that the asset class weights sum to one and that all weights are non-negative. The model is:

$$
r_{i t}=\sum_{j=1}^{r} \beta_{j} R_{j}+\varepsilon_{i}
$$

where $r_{i t}$ is the monthly return for robo-advisor $i$ and $R_{j}$ is the monthly return for asset class $j$. We further require $\sum_{j=1}^{r} \beta_{j}=1$ and $\beta_{j} \geq 0 \forall j=1, \ldots, 5$. The estimates for $\beta_{j}$ are reported in Table 11 .

The selection of asset classes for our style analysis seems to be suitable: between $88.3 \%$ (SutorBank) and 94.6\% (Easyfolio) of returns can be explained by exposures to the five asset classes. We report the explained $R^{2}$ and unexplained parts of the return variability in Table 12 . 
Table 11. Estimated asset allocation for robo-advisors and benchmark

\begin{tabular}{lc|c|c|cc}
\hline \multicolumn{7}{c|}{$\begin{array}{c}\text { Bonds DM } \\
(\%)\end{array}$} & $\begin{array}{c}\text { Equity DM } \\
(\%)\end{array}$ & $\begin{array}{c}\text { Equity EM } \\
(\%)\end{array}$ & $\begin{array}{c}\text { TIPS } \\
(\%)\end{array}$ & $\begin{array}{c}\text { Commodities } \\
(\%)\end{array}$ \\
\hline Easyfolio & 35.2 & 38.3 & 13.9 & 11.7 & 1.0 \\
\hline Fintego & 27.7 & 43.3 & 3.4 & 23.5 & 2.1 \\
\hline Quirion & 42.6 & 48.8 & 7.0 & 0.0 & 1.6 \\
\hline SutorBank & 37.8 & 47.6 & 14.6 & 0.0 & 0.0 \\
\hline Vaamo & 45.6 & 40.5 & 13.9 & 0.0 & 0.0 \\
\hline \multicolumn{7}{|c|}{ Benchmark } & 0.0 \\
\hline Before fees & 50.0 & 50.0 & 0.0 & 0.0 & 0.0 \\
\hline
\end{tabular}

Source: author.

Table 12. Explained and unexplained return variability for robo-advisors

\begin{tabular}{lcc}
\hline & Explained & Unexplained \\
\hline Easyfolio & 94.6 & 5.4 \\
\hline Fintego & 90.1 & 9.9 \\
\hline Quirion & 90.1 & 9.9 \\
\hline SutorBank & 88.3 & 11.7 \\
\hline Vaamo & 88.7 & 11.3 \\
\hline
\end{tabular}

Source: author.

In general, the results of our style analysis confirm the reported asset allocation of the robo-advisors. All robo-advisors in our sample have roughly $50 \%$ exposure to equity and $50 \%$ to bonds. However, when one looks deeper, one finds several deviations from the reported asset allocation. Fintego, for example, seems to have a large exposure to TIPS according to our style analysis, but the reported asset allocation does not mention TIPS as a target asset class. According to the company's website, Fintego invests into commodities, which, on the other hand, only shows up as a very small percentage in our style analysis. The reason could be our relatively small historical sample of only 44 monthly returns. Furthermore, our asset class universe might not be suited for all investment styles: Fintego invests only in European government bonds and corporate bonds. Other robo-advisors allocate assets not geographically but according to factors, e.g. value or growth.

In order to compare the styles of the different robo-advisors, we calculate their common style ${ }^{5} \mathrm{CS}_{i j}$ as the sum of the overlap of the exposure to the individual asset classes as follows:

5 A concept used for example by Markov Processes International, Inc. 


$$
C S_{i j}=\sum_{a=1}^{5} \min \left\{\beta_{i, a}, \beta_{j, a}\right\} \text {, }
$$

where $\beta_{i, a}$ denotes the exposure of robo-advisor $i$ to asset class $a$. We report the common style for the five robo-advisors in our sample in Table 13.

Table 13. Common style in percentage points for robo-advisors

\begin{tabular}{|lc|c|c|cc|}
\hline & Easyfolio & Fintego & Quirion & SutorBank & Vaamo \\
\hline Easyfolio & 100.0 & 82.1 & 81.5 & 87.4 & 87.4 \\
\hline Fintego & 82.1 & 100.0 & 76.0 & 74.4 & 71.6 \\
\hline Quirion & 81.5 & 76.0 & 100.0 & 92.4 & 90.1 \\
\hline SutorBank & 87.4 & 74.4 & 92.4 & 100.0 & 92.2 \\
\hline Vaamo & 87.4 & 71.6 & 90.1 & 92.2 & 100.0 \\
\hline
\end{tabular}

Source: author.

The result shows that the investment style of robo-advisors is very similar. Quirion and SutorBank seem to have the same style, i.e. the same exposure to asset classes. Fintego is the robo-advisor that differs in its investment style most from its peers.

Style analysis enables us also to create mimicking portfolio for reach roboadvisor, which can provide further performance insights. We calculate the mimicking portfolio returns as follows:

$$
r_{i t}=\sum_{j=1}^{r} \beta_{j} R_{j t},
$$

where $r_{i t}$ is the return of mimicking portfolio for robo-advisor $i$ and $R_{j t}$ is the monthly return for asset class $j$. The resulting summary statistics of mimicking portfolio returns are reported in Table 14.

Table 14. Summary statistics for mimicking portfolio returns

\begin{tabular}{ll|l|l|l|ll}
\hline Mimicking Portfolio & $\begin{array}{c}\text { Arithmetic } \\
\text { Mean (\%) }\end{array}$ & $\begin{array}{c}\text { Standard } \\
\text { Deviation } \\
(\%)\end{array}$ & Skewness & $\begin{array}{c}\text { Excess } \\
\text { Kurtosis }\end{array}$ & Min (\%) & Max (\%) \\
\hline Easyfolio & 0.166 & 1.717 & -0.338 & 1.036 & -4.255 & 4.788 \\
\hline Fintego & 0.137 & 1.718 & -0.384 & 1.275 & -4.455 & 4.824 \\
\hline Quirion & 0.161 & 1.874 & -0.436 & 1.064 & -4.750 & 5.123 \\
\hline SutorBank & 0.168 & 2.044 & -0.465 & 1.216 & -5.390 & 5.622 \\
\hline Vaamo & 0.150 & 1.791 & -0.440 & 1.255 & -4.777 & 4.941 \\
\hline
\end{tabular}

Source: author. 


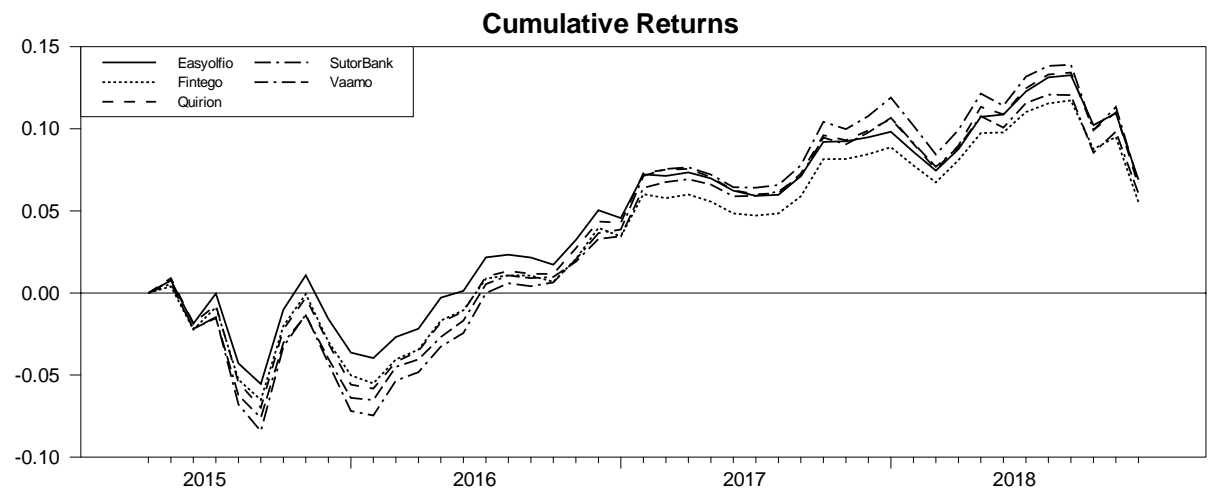

Figure 5. Cumulative returns of mimicking portfolios

Source: author.

When we compare Table 14 and Table 2, we observe that the mimicking portfolios have nearly the same volatility as the original portfolios. The means of the mimicking portfolios are higher since these are before-fee returns. What is evident from Figure 5 on the cumulative returns of mimicking portfolios is that differences in factor exposures alone cannot explain the observed differences in mean returns. The returns of Easyfolio and Vaamo should have been nearly identical given the estimated exposures to asset classes but from Table 5 we know that Vaamo returned cumulatively 5.2\% more than Easyfolio until December 2018.

In addition, management fees cannot explain the Easyfolio-Vaamo difference since Vaamo charges about 13 bps p.a. more than Easyfolio. We can also safely assume that the average ETF-management fees charged by the funds, in which the robo-advisors invest, are similar.

Table 15. Robo-advisor fees

\begin{tabular}{lc}
\hline & Annual management fee \\
\hline Easyfolio & $0.66 \%$ \\
\hline Fintego & $0.95 \%$ \\
\hline Quirion & $0.48 \%$ \\
\hline SutorBank & $0.70 \%$ \\
\hline Vaamo & $0.79 \%$ \\
\hline
\end{tabular}

Source: Finanztest (2017). 
Given the way robo-advisors manage money and if asset allocation and management fees cannot explain the performance differences, then the following characteristics must be the reason. First, exposure to other factors. Vaamo's style analysis only explained $89 \%$ of the return variability; $11 \%$ remains unexplained. This $11 \%$ might result from exposure to asset classes/factors (e.g. small cap, value stocks, or momentum) that our analysis did not include. This is even more plausible since Vaamo invests into funds managed by US fund manager Dimensional Fund Advisors, which is famous for employing the Fama/French (1993) factor methodology. Second, portfolio implementation might play a role. The specific funds the robo-advisor invests in and how the fund buys and sells these ETFs may differ. In addition, the portfolio management techniques of the ETFs play a role. Third, rebalancing is important, i.e. how and how often the current portfolio weights are brought back to the target weights. If re-balancing is done at (ex-post) not optimal points in time, it has a negative effect on portfolio performance.

\section{CONCLUSIONS}

We analyzed monthly return data for five German robo-advisors over the May 2015 - December 2018 period. We documented significant performance differences between some of these robo-advisors. Using returns-based style analysis, we found their effective asset mix. Mimicking portfolios have been constructed for each robo-advisor and using these, we tried to explain differences in performance with differences in asset allocation. We found that differences in asset allocation cannot fully explain the observed differences in performance between different robo-advisors. Alternative reasons for these performance differences include missing factors, portfolio implementation, and re-balancing.

This result is significant since we demonstrated that portfolios with a similar (stated) asset mix of around $50 \%$ bonds and $50 \%$ equities (which would be suitable for people with a similar risk preference) can show large differences performance. Hence, finding the right robo-advisor is of critical importance.

Given the ongoing debate about the relative merits of traditional financial advice and robo-advice, it would also be interesting to contrast performances between portfolios recommended by traditional financial advisors and robo-advisors for the same person. Robo-advisors typically recommend a portfolio based on very few data points / attributes from a client. A traditional financial advisor would be able to use much more information from the client in order to recommend a portfolio that would be much more suitable for them. 


\section{REFERENCES}

A. T. Kearney (2015): Hype vs. Reality. The Coming Waves of 'Robo'Adoption. Robo-Advisory Services Study, June. https://www.atkearney.com/documents/10192/7132014/Hype+vs.+Reality_ The+Coming+Waves+of+Robo+Adoption.pdf, accessed 31/05/2019.

Backend Benchmarking (2019): The Robo Report, https://www.backendbenchmarking.com/therobo-report/, accessed 31/05/2019.

Barron's (2017): Rating the Robo-Advisors, 29 July 2017. https://www.barrons.com/articles/ratingthe-robo-advisors-1501303316, accessed 31/05/2019.

Bhargava, R. - Gallo, J. G. - Swanson, P. E. (2001): The Performance, Asset Allocation, and Investment Style of International Equity Managers. Review of Quantitative Finance and Accounting 17(4): 377-395.

Black, F. - Litterman, R. (1992): Global Portfolio Optimization. Financial Analysts Journal 48(5): 28-43.

BrokerVergleich (2019): Robo Advisor - Statistiken und Daten [Statistics and Data]. https://www. brokervergleich.de/robo-advisor/statistiken, accessed 31/05/2019.

Extra-Magazin (2017): So groß ist der Robo-Advisor-Markt in Deutschland [The Market for Robo Advisors in Germany]. https://www.extra-funds.de/news/etf-news/robo-advisor-markt-indeutschland, accessed 1/11/2017.

Fama, E. F. - French, K. R. (1993): Common Risk Factors in the Returns on Stocks and Bonds. Journal of Financial Economics 33(3): 3-56.

Finanztest (2017): Beratung ist Programm [Advice is Program]. Finanztest 01/2017, 56-63.

Fisch, J. E. - Labouré, M. -Turner, J. A. (2018): The Emergence of the Robo-Advisor. Pension Research Council Working Paper WP2018-12.

IDC (2017): Robo-Advisory: Changing the Face of Wealth in Asia/Pacific, https://www.idc.com/ getdoc.jsp?containerId=AP43074317, accessed 10/11/2017.

Jensen, M. C. (1968): The Performance of Mutual Funds in the Period 1945-1964. Journal of Finance 23: 389-416.

Koreto, R. J. (2002): Robo-Advisor: In a New World of Intense 401(k) Anxiety Brought about by the Enron Fiasco, the Only Hand Investors may Have to Hold may Be Digital. Financial Planning, March.

Lam, J. W. (2016): Robo-Advisors: A Portfolio Management Perspective. Thesis, Yale College. https://economics.yale.edu/sites/default/files/files/Undergraduate/Nominated\%20Senior\%20 Essays/2015-16/Jonathan_Lam_Senior\%20Essay\%20Revised.pdf, accessed 23/06/2019.

Markowitz, H. M. (1952): Portfolio Selection. The Journal of Finance 7(1): 77-91.

Michaud, R. O. (1989): The Markowitz Optimization Enigma: Is ‘Optimized’ Optimal? Financial Analysts Journal 45(1): 31-42.

Micobo (2018): Developments of the Robo Advisory Market in Germany 2018, https://medium. com/@micobo/develoments-of-the-robo-advisory-market-in-germany-2018-3821cf240da1, accessed 31/05/2018.

Puhle, M. (2016): The FinTech Revolution: A Closer Look at Robo-Advisors, Finance \& Economy 2017(4): 256-271.

Sharpe, W. F. (1964): Capital Asset Prices: A Theory of Market Equilibrium under Conditions of Risk. Journal of Finance 19(3): 425-442.

Sharpe, W. F. (1992): Asset Allocation: Management Style and Performance Measurement. Journal of Portfolio Management 18(2): 7-19.

TechFluence (2017): Robo Advice in Germany - A Summer Update http://www.techfluence.eu/ investtech.html, accessed 10/11/2017. 
Open Access. This is an open-access article distributed under the terms of the Creative Commons Attribution 4.0 International License (https://creativecommons.org/licenses/ by/4.0), which permits unrestricted use, distribution, and reproduction in any medium, provided the original author and source are credited, a link to the CC License is provided, and changes - if any - are indicated. (SID_1) 